quite unjustified in view of our projected halt to the smallpox/whitepox work at the end of the year". Dr I. Arita, chief of the WHO's Smallpox Eradication Unit in Geneva, assured Bedson that the expected benefit of his study "far exceeded the minimal risk" currently present in his laboratory and that the visiting team would understand his situation.

The three inspectors, however, were very critical of the safety precautions taken at the laboratory. They recommended that all mouth pipetting be prohibited, that back fastening gowns which would remain in the laboratory be worn, that hypochlorite solution be used as a permanent barrier in sinks and that gloves be worn for all work with infectious materials.

On 2 June Bedson replied to these criticisms. He accepted the suggestions concerning the use of hypochlorite solution and the wearing of gloves but argued that mouth-pipetting had not been used with smallpox for ten years. The WHO team had observed a 'tem- porary aberration' which would not happen again whereby mouth-pipetting was used in connection with an animal poxvirus. He also argued that back fastening gowns were used in the smallpox lab and not in the animal pox lab so that they could be distinguished.

One inspector, however, was not satisfied. He was concerned about the lack of a shower, the lack of secondary containment in the animal poxvirus lab where smallpox viruses were stored and the performance and maintainence of the biological safety cabinet in the smallpox room. He recommended that the laboratory be upgraded to meet the WHO standards or "discontinue work with variola at the earliest possible date".

The next letter Bedson wrote was on 24 August when he returned from holiday. Later that day he was to find brick-shaped particles characteristic of poxviruses in vesicle fluid specimens from Mrs Parker but at the time he wrote the letter smallpox had not been diagnosed. "There is no question", he wrote, "of our being able to upgrade our facilities to meet the full WHO standards and we are therefore proceeding with our plans to complete our studies with varola/whitepox virus by the end of this year".

What Bedson seems to have never mentioned in any of his correspondence was that the amount of smallpox work in his lab had actually increased substantially. In his letter of 2 June, he even says that there had been "a progressive decline in the scale and diversity of our operations, particularly since 1973". The Shooter inquiry found otherwise. In particular shortly after Bedson wrote this letter the rate of work increased even more as work began on 22 variola strains received from St. Mary's Hospital, London, on 26 May. Dr Mary Darlow, ex-safety officer of the Porton germ warfare establishment, commented last week :

"Bedson knew he was backing a lame horse and that it would stumble sooner or later. It stumbled sooner".

\title{
Bedson's concern: could smallpox re-emerge?
}

RIFT valley fever is a cattle disease with a mortality rate of $80 \%$. It is endemic in Egypt and recently has begun to affect man. The Egyptian authorities estimate that 18,000 people have so far caught the disease but, according to Professor Arie Zuckerman of the London School of Hygiene and Tropical Medicine (LSHTM), a team from the school which recently visited Egypt puts the number at nearer 200,000. Without suitable facilities for diagnosis and research, says Professor Zuckerman, it would be difficult to see how the spread of Rift valley fever could be prevented in Europe once the disease had crossed the Suez canal.

The situation with other diseases is similar. Early diagnosis of rabies or new diseases such as lassa fever or Marburg disease means that they can be contained. Having suitable research facilities means that vaccine and treatment can be developed in case of an outbreak.

Research is also important, however, for predicting new diseases. In the case of smallpox, for example, eradication was possible because of the existence of a very effective vaccine and because it appears to have no animal reservoir or insect vector. What worries microbiologists now, however, is that poxviruses very similar to the smallpox virus which currently affect only animals may begin to affect humans. Research on the similarities between different poxviruses and their relationship to smallpox might therefore indicate how likely this is.
The first poxvirus to be identified in a non-human primate was monkeypox virus which was isolated in 1958. Since then it has been isolated from nonhuman primates on several occasions and has been responsible for about 30 cases of human monkeypox in West and Central Africa between 1970 and 1978. Fortunately the spread of human monkeypox from man to man is extremely rare.

Another poxvirus very closely related to smallpox is whitepox. It was first isolated from the kidneys of cynomolgus monkeys in 1964 and it is still impossible to distinguish it from smallpox virus by laboratory tests.

The work at Birmingham centred on the identification and differentiation of poxviruses. Early work had tried to distinguish viruses by looking at the enzymes they produce. More recent work, however, had used a technique called polyacrylamide gel electrophoresis (PAGE) to separate out the polypeptide constituents of viruses and then compare them.

By mid-1978 the Birmingham team had completed comparisons of 41 different poxviruses using PAGE techniques. It had found that all but three could be put into one of four basic categories. The smallpox/whitepox category of viruses could be subdivided into types $\mathbf{A}$ and $\mathbf{B}$. When a report of the findings was written for the WHO much more work was planned on the differentiation of types $A$ and B smallpox viruses. Most of the $B$ viruses seemed to be of Middle Eastern or Pakistani origin whereas the
A viruses had mainly originated in Africa. Whitepox viruses were also found to subdivide into types $\mathbf{A}$ and $\mathbf{B}$, the $B$ type originating in Asia and the A type in Africa. "This supports the view", said the report "that these (whitepox viruses) must be regarded as smallpox viruses".

After the extensive study of smallpox/whitepox viruses which was to have finished at the end of 1978, the Birmingham laboratory was planning to continue its study of animal pox viruses. Minor differences had been observed between some of the cowpoxlike viruses and some of the monkeypox-like viruses, said the report, and those should be the subject of further study.

- The WHO says that to the best of its knowledge the only laboratories holding smallpox viruses are the following: National Institute for Virology, South Africa; Centre for Disease Control, Atlanta, USA; American Type Culture Collection, New York, USA; Walter Reed Army Institute of Research, Washington, USA; Bayerische Landesimpfanstalt, Munich, West Germany; Institut fur Schiffs und Tropenkrankheiten, Hamburg, West Germany; Rijks Institut voor de Volksgezondheid, Bilthoven, Netherlands; Laboratory of Smallpox Prophylaxis, Research Institute of Viral Preparations, Moscow, USSR; Virology Department, St Mary's Hospital Medical School, London, UK; Institute for Control of Drugs and Biological Products, Peking, China. 